\title{
ARTICLE OPEN \\ Atlantic Ocean influence on Middle East summer surface air temperature
}

\author{
Muhammad Azhar Ehsan (iD ${ }^{1,2,3 *}$, Dario Nicoli ${ }^{4}$, Fred Kucharski ${ }^{2,3}$, Mansour Almazroui ${ }^{3}$, Michael K. Tippett ${ }^{5}$, Alessio Bellucci $^{4}$, \\ Paolo Ruggieri ${ }^{4}$ and In-Sik Kang ${ }^{6}$
}

Middle East surface air temperature (ME-SAT), during boreal summer (June to August: JJA), shows robust multidecadal variations for the period 1948-2016. Here, using observational and reanalysis datasets, as well as coupled atmosphere-ocean model simulations, we linked the observed summer ME-SAT variability to the multidecadal variability of sea surface temperature (SST) in the North Atlantic Ocean (AMV). This Atlantic-ME connection during summer involves ocean-atmosphere interactions through multiple ocean basins, with an influence from the Indian Ocean and the Arabian Sea. The downstream response to Atlantic SST is a weakening of the subtropical westerly jet stream that impacts summer ME-SAT variability through a wave-like pattern in the upper tropospheric levels. The Atlantic SST response is further characterized by positive geopotential height anomalies in the upper levels over the Eurasian region and a dipole-like pressure distribution over the ME in lower levels. For positive Atlantic SST anomalies this pressure gradient initiates anomalous low-level southerly flow, which transports moisture from the neighboring water bodies toward the extremely hot and dry ME landmass. The increase in atmospheric moisture reduces the longwave radiation damping of the SAT anomaly, increasing further ME-SAT. A suite of Atlantic Pacemaker experiments skillfully reproduces the North Atlantic-ME teleconnection. Our findings reveal that in observations and models the Atlantic Ocean acts as a critical pacemaker for summer MESAT multidecadal variability and that a positive AMV can lead to enhanced summer warming over the Middle East.

npj Climate and Atmospheric Science (2020)3:5; https://doi.org/10.1038/s41612-020-0109-1

\section{INTRODUCTION}

The Middle East (Supplementary Fig. 1a) climate exhibits variability on a wide range of timescales. Understanding the nature and drivers of this multi-scale climate variability is a fundamental step in developing robust climate predictions and risk assessments over the ME. For instance, changes in surface air temperature significantly influence all socioeconomic sectors, ${ }^{1}$ including but not limited to water resources, power management, crop growth, food security, agro-ecological zoning, industrial development, tourism, and people's daily activity all around the world. ${ }^{2-6}$ The annual cycle of ME-SAT (Supplementary Fig. 1b) reveals that the highest temperatures occur from June through August, with July as the hottest month, and boreal summer as the hottest season (Supplementary Fig. 1c). Surface air temperature over the ME shows a statistically significant positive ${ }^{7,8}$ trend $\left(0.28^{\circ} \mathrm{C} /\right.$ decade) with accelerated warming from the $1980 \mathrm{~s}$ (Supplementary Fig. 1d: red curve), which is projected to continue into the future. ${ }^{9}$ Detrended summer ME-SAT shows multidecadal variability with some periods (e.g., the 1960s to 1980s) having less pronounced warming (Supplementary Fig. 1d: blue curve). This study investigates possible reasons for such fluctuations around the mean warming trend. The topic has a high societal relevance, because during the next decade, "Hajj", the largest annual gathering (several million) of Muslims, will occur during boreal summer. Millions of Muslims from across the world will travel to Saudi Arabia to perform the Hajj Pilgrimage in the Holy city of Makkah and spend part of that time outdoors. The exact dates for this ritual are determined according to the lunar calendar (in 2019, from 9 to 24 August) and consequently can occur during the summer months for several consecutive years (in 2020, it will occur from 28 July to 2 August). Therefore, knowing the physical mechanism of the SAT variability during summer could inform government agencies in adopting timely appropriate mitigation and adaption strategies that may provide ease and comfort to Pilgrims.

The Atlantic Ocean has been recognized as an important driver of decadal variability in the Northern Hemisphere. ${ }^{10-13}$ The Atlantic Multidecadal Oscillation (AMO) ${ }^{14}$ or variability (AMV) is a leading mode of observed sea surface temperature (SST) variability in the North Atlantic on a multidecadal timescale, ${ }^{15,16}$ which can be skillfully predictable on multiyear timescale. ${ }^{17}$ The instrumental records show that AMO/AMV is associated with a natural fluctuation of basin-wide anomalously warm and cold phases, with a preferential period of roughly 40-80 years. ${ }^{14}$ Paleoclimate records also show similar periods for AMO/AMV. ${ }^{18,19}$ The AMO/AMV has been recognized to impact the global climate, particularly over the Northern Hemisphere, on multidecadal timescale. On the regional and local scale, it drives the climate of North America and western Europe, ${ }^{12,20}$ influences the global monsoon, ${ }^{21,22}$ controls Sahel rainfall, ${ }^{23,24}$ and impacts Eurasian climate $^{25,26}$ and the South Asian summer monsoon. ${ }^{27}$

Several studies have examined the dominant modes of surface air temperature variability over different regions of Eurasia during different seasons, ${ }^{28,29}$ including some studies specifically focusing on the Middle East-North Africa region. ${ }^{30-34}$ The summertime climate variations of the ME were linked in these studies to various large-scale and regional processes, such as El Nino-Southern Oscillation, Indo-Pacific warm pool, tropical North and South

\footnotetext{
${ }^{1}$ International Research Institute for Climate and Society (IRI), Earth Institute at Columbia University, Palisades, NY, USA. ${ }^{2}$ Earth System Physics Section, International Centre for Theoretical Physics (ICTP), Trieste, Italy. ${ }^{3}$ Center of Excellence for Climate Change Research (CECCR), King Abdulaziz University, Jeddah, Saudi Arabia. ${ }^{4}$ Fondazione CMCC —Centro Euro-Mediterraneo sui Cambiamenti Climatici, Bologna, Italy. ${ }^{5}$ Department of Applied Physics and Applied Mathematics, Columbia University, New York, NY, USA. ${ }^{6}$ Indian Ocean Operational Oceanography Research Center, SOED, Second Institute of Oceanography, Hangzhou, China. *email: azhar.ehsan82@gmail.com
} 
Atlantic, Western Hemisphere warm pool, the North Atlantic and Arctic Oscillations, as well as the South Asian summer monsoon through the well-known monsoon-desert mechanism. ${ }^{35}$ However, the spatial and temporal structures of the dominant mode of boreal summer ME-SAT, and particularly the main factors responsible for summer SAT anomalies related to the leading variability mode are less understood. Links between summer MESAT and Atlantic SST have received even less scientific attention, ${ }^{36}$ despite the potential for synergistic effects that might favor highimpact extreme events, particularly record-breaking summer temperatures and extreme heat waves. ${ }^{37-39}$

In this study, we examine the impact of North Atlantic SST variation, one of the main drivers for Northern Hemisphere climate, on summer ME-SAT. We show that the leading mode of summer ME-SAT variability is strongly correlated with the internal multidecadal mode of variability in the North Atlantic, and that the strong recent warming trend over the ME could persist as long as the North Atlantic Ocean remains anomalously warm. Furthermore, the relative significance of induced circulation and related physical mechanisms in observation and reanalysis datasets, as well as an ensemble of idealized pacemaker experiments are discussed.

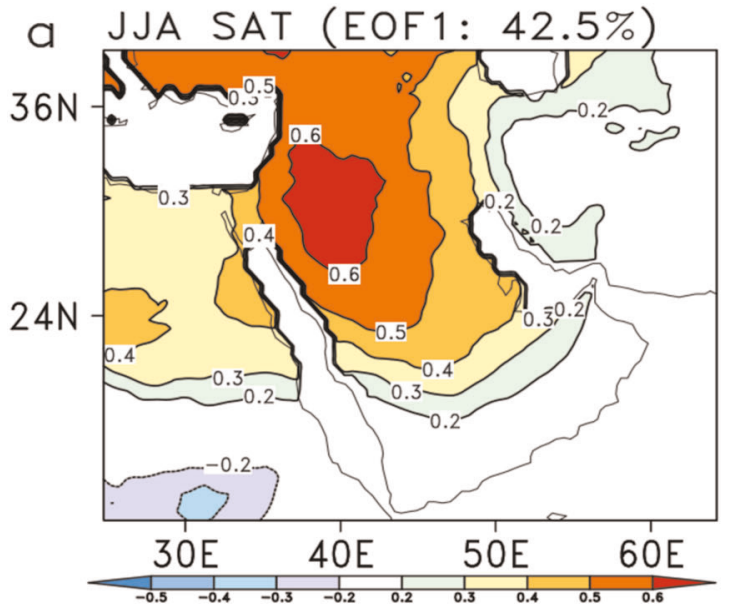

\section{RESULTS}

Defining summer ME-SAT index and its association with Atlantic We first define an index using the leading empirical orthogonal function (EOF1) of detrended (see methods) summer SAT over the ME domain (Fig. 1a). The leading mode explains $42.5 \%$ of the total variability, and it is characterized by positive SAT anomalies over the whole area. The pattern shows a meridional gradient with substantial variations over the northern regions. The associated principal component (PC1) time series exhibits strong multidecadal variations (Fig. 1c: red curve). We first investigate the nature of the relationship between the leading mode of summer ME-SAT and global surface temperature field both over land and ocean (see data). Figure $1 \mathrm{~b}$ shows the spatial distribution of correlation between PC1 of summer ME-SAT and surface temperature for the period 1948-2016. The PC1 of summer MESAT is highly positively correlated over the whole region and large parts of Eastern Europe and Mediterranean region. The most prominent feature in Fig. $1 \mathrm{~b}$ is a strong positive association of PC1 of summer ME-SAT with SST in the North Atlantic Ocean. Other noticeable features are the weak signals in the Pacific and Indian basins. A recent study ${ }^{40}$ discussed the interannual variability of the summer SAT over the Arabian Peninsula (AP) and its association with SST anomalies in the Pacific region. We also found similar results for summer AP-SAT and SST in the Pacific for the two distinct periods considered in that study, while no signal appears

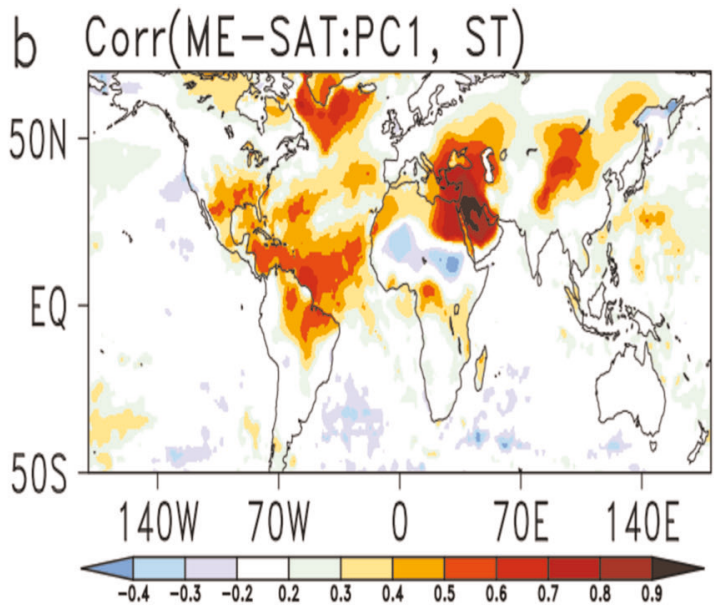

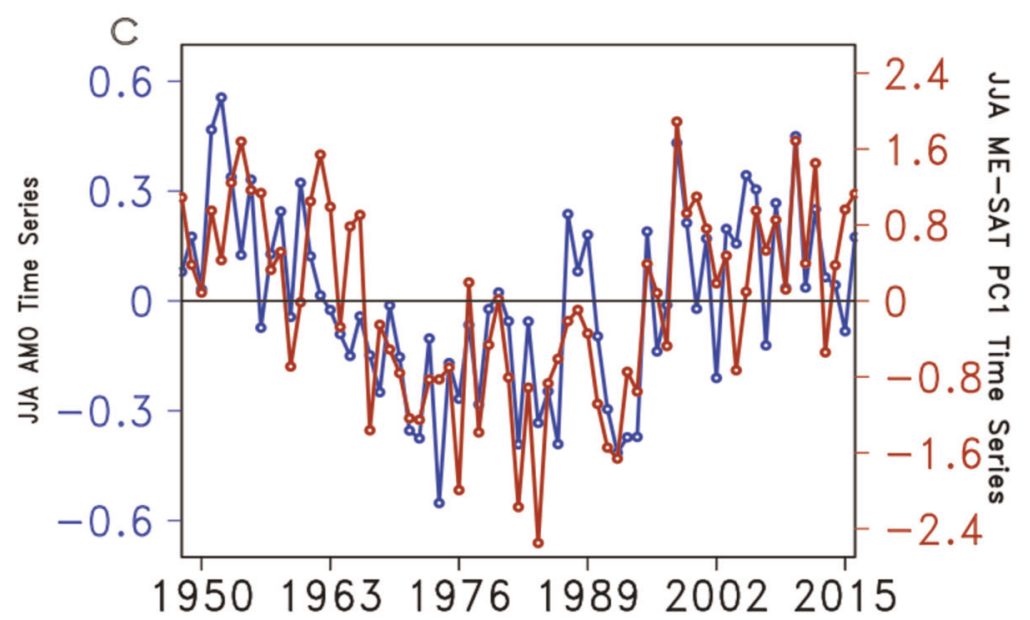

Fig. 1 Observed summer (June to August) surface air temperature variability in the Middle East. a Leading empirical orthogonal function (EOF1) of detrended summer ME-SAT anomalies during the period 1948-2016 with explained variance. $\mathbf{b}$ The correlation of summer ME-SAT PC1 time series to the global surface temperature (Land and Ocean) anomalies. The CRU surface temperature is used over land and HadISST data is used over the ocean for 69 years (1948-2016). Color regions (Fig. 1b) display significant values by using MC method with 95\% confidence level. c The associated principal component (PC1) summer ME-SAT (red curve) and AMO SST time series (blue curve). 

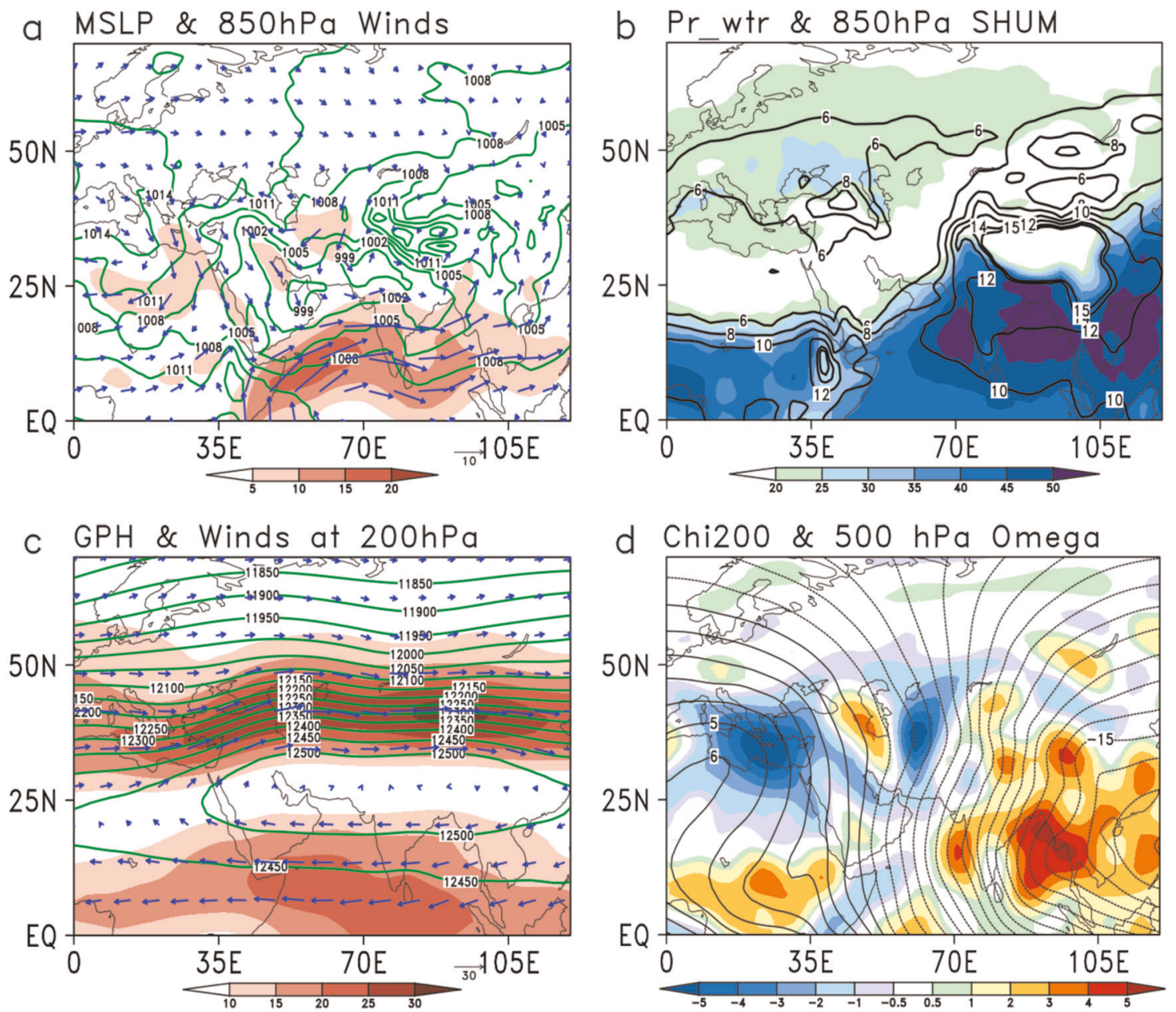

Fig. 2 Large-scale atmospheric circulation pattern over ME during summer. Long-term mean background states of boreal summer a mean sea level pressure (contour: hPa), $850 \mathrm{hPa}$ winds (vectors: $\mathrm{m} \mathrm{s}^{-1}$ ), and speed (shaded: $\mathrm{m} \mathrm{s}^{-1}$ ), b precipitable water (shading: kg $\mathrm{m}^{-2}$ ) and specific humidity at $850 \mathrm{hPa}$ (contour: $\mathrm{g} \mathrm{kg}^{-1}$ ), c $200 \mathrm{hPa}$ geopotential height (contour: $\mathrm{m}$ ), winds (vectors: $\mathrm{m} \mathrm{s}^{-1}$ ) and speed (shaded: $\mathrm{m} \mathrm{s}^{-1}$ ), d $200 \mathrm{hPa}$ velocity potential showing contour interval 1 (contour: $\times 1 \mathrm{e}+06 \mathrm{~m}^{2} \mathrm{~s}^{-1}$ ), and $500 \mathrm{hPa}$ omega (shaded: $-\mathrm{Pa}$ min ${ }^{-1}$ ), in which blue (red) colors denote descending (ascending) motion.

in the Pacific region if we consider full period (Supplementary Fig. 2). Nevertheless, the Atlantic response is steady and robust for all periods. ${ }^{36}$ The unfiltered AMO index (Fig. 1c: blue curve), which is defined here as the spatially averaged detrended SST anomalies over the North Atlantic Ocean (ATL: $75^{\circ} \mathrm{W}$ to $7.5^{\circ} \mathrm{W}, 0^{\circ}$ to $60^{\circ} \mathrm{N}$ ), shows similar variations to PC1 of summer ME-SAT (Fig. 1c: red curve). The correlation between the leading mode of the summer ME-SAT and spatially averaged SST anomalies in the ATL region is 0.71 , which indicates a close correspondence of ME-SAT with the SST variations in the North Atlantic basin during summer (Fig. 1c).

Atlantic influence on the moisture transport from the Indian ocean and local longwave radiation feedback on the ME-SAT

To understand the underlying physical mechanism of the ME-SAT and ATL-SST relationship, we first discuss the long-term boreal summer atmospheric properties over the region. An intense thermal low (Fig. 2a) is located over east (centered over Arabian Gulf) of the Arabian Peninsula, while high-pressure resides in the upper levels (Fig. 2c). The prevailing lower level winds at $850 \mathrm{hPa}$ are northerly over the region and relatively stronger winds $\left(5-10 \mathrm{~m} \mathrm{~s}^{-1}\right)$ are observed over the Red Sea and the Arabian Gulf, while a stronger low-level jet $\left(15-20 \mathrm{~m} \mathrm{~s}^{-1}\right)$ is dominant further south of the AP over the Arabian Sea. Long-term summer seasonal mean atmospheric precipitable water and specific humidity at
$850 \mathrm{hPa}$ show an evident moisture contrast between main landmass and coastal regions, with abundant moisture available along the Arabian Sea coast (Fig. 2b). The ME region lies between two strong jets: the subtropical jet stream in the north and the tropical easterly jet in the south during summer (Fig. 2c). The presence of a prevailing high-pressure system in upper levels and strong subsidence motion (Fig. 2d) favors clear skies and blazing sunshine that results in scorching summer over the entire region. ${ }^{41}$

To investigate how summer, ME-SAT is influenced by the Atlantic Ocean, simple linear regression of summer SAT on the normalized ATL-SST index is performed. Interestingly, the regression pattern (Fig. 3a) show positive values over the entire domain and resembles the leading EOF mode of the summer ME-SAT (Fig. 1a). This is a strong indication that the summer ME-SAT fluctuations are controlled by the Atlantic SST. The raw summer ME-SAT and Atlantic SST show significant global warming trends for the period 1948-2016 (Supplementary Fig. 1d). Therefore, we reexamine the relationship based on the raw data. The in-phase relationship between raw summer ME-SAT PC1 and Atlantic SST remains strong and robust. Furthermore, the relationship between summer ME-SAT and ATL-SST is consistent across different SST and SAT datasets, indicating that the results are robust and not sensitive to the particular choice of datasets (Supplementary Fig. 3). These results suggest that basin-wide North Atlantic SST 

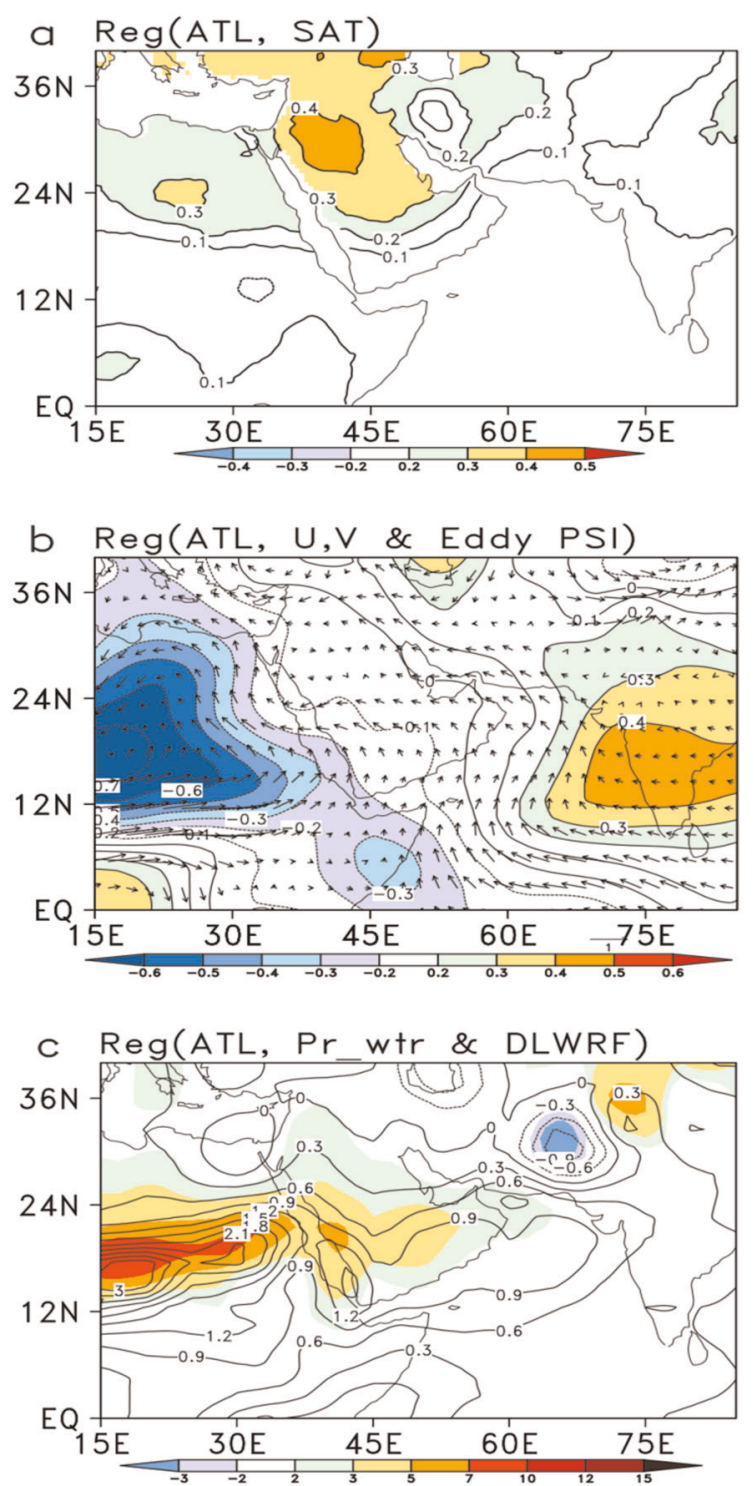

Fig. 3 Observed control of Atlantic in lower troposphere over ME region. The regression of normalized Atlantic SST index (spatially averaged SST anomalies over $75^{\circ} \mathrm{W}$ to $7.5^{\circ} \mathrm{W}$ and $0^{\circ} \mathrm{N}$ to $60^{\circ} \mathrm{N}$ ) onto a SAT (shaded: ${ }^{\circ} \mathrm{C}$ ), $\mathbf{b}$ the eddy stream function (shaded: $\times 1 \mathrm{e}+$ $06 \mathrm{~m}^{2} \mathrm{~s}^{-1}$ ) and winds at $850 \mathrm{hPa}$ (vector: $\mathrm{m} \mathrm{s}^{-1}$ ), c precipitable water (contour: $\mathrm{kg} \mathrm{m}^{-2}$ ) and downward longwave radiation flux (shaded: $\mathrm{W} \mathrm{m}^{-2}$ ). Color regions display significant values by using $\mathrm{MC}$ method with $95 \%$ confidence level.

warming is closely associated with warmer than normal conditions over the ME, and conversely, basin-wide North Atlantic SST cooling is closely associated with cooler than normal conditions over the ME.

Connections between the summer ME-SAT and the dominant decadal mode in Atlantic Ocean are further investigated in atmospheric circulation variables. Figure $3 \mathrm{~b}$ shows the regression of ATL-SST time series to the eddy stream function (shaded) and winds at $850 \mathrm{hPa}$ (vectors). The lower level eddy stream function clearly shows an East-West dipole structure with high pressure dominating in the east and low pressure in the west. The pressure gradient initiates anomalous southerly flow, which transports moisture (Fig. 3c: contour) toward the ME. Consequently, atmospheric moisture increases over the central and northern latitudes of $\mathrm{ME}$, and the atmosphere absorbs more longwave radiation emitted by the surface, warming the atmosphere and the surface
(Fig. 3c: shaded). It is quite surprising that the summer SAT and surface radiative fluxes are highly sensitive to changes in atmospheric moisture, particularly over the northern areas of the $\mathrm{ME}$ as compared to the southern latitudes. The cause of this disparity is the moisture transport from neighboring water bodies and local longwave radiation feedback on the SAT. This is further supported by the analysis of ATL-SST index regression on the downward shortwave radiation flux at the surface (Supplementary Fig. 4). In southern regions, the increase in water vapor is associated with an increase in downward longwave radiation. However, here the additional radiative energy flux at the surface can trigger convective activity, leading to an increase in precipitation, ${ }^{42,43}$ and a decrease in downward shortwave radiation at the surface, that reduces the SAT warming over the southern parts of the ME (Supplementary Fig. 4).

The observational analysis provides us with compelling evidence that the Atlantic Ocean is a key driver of decadal variability in the Middle East Mediterranean region. This is further supported by the regression of filtered AMO index (smoothed by 11 year running mean) on eddy stream function, lower level winds, precipitable water, downward longwave radiation flux, and surface air temperature (Supplementary Fig. 5). The unfiltered and filtered summer ME-SAT connection with ATL-SST confirms the robustness of results presented here. Further evidence for the relation between ALT-SST and summer ME-SAT is provided by the consistency between the observed pattern of anomalies, and the one emerging from idealized climate simulations in which the Atlantic Ocean is unambiguously identified as the responsible driver.

\section{Modeling evidence}

Observations largely support the local moisture-longwave radiation feedback as being one of the major factors responsible for the ME-SAT variations during summertime. Previous idealized modeling experiments using the SPEEDY AGCM (see the models and experiments) showed that large and persistent Atlantic SST anomalies force low-level convergent flow, bringing moist air during the African and Indian summer monsoon and modulating the summer climate over these regions. ${ }^{44-46}$ This motivates us to examine further the suggested mechanism for the ME-SAT variability using the SPEEDY AGCM. For the current research, the model is configured using an Atlantic Pacemaker experimental setup, in which observed SST is prescribed in the Atlantic region and a mixed-layer slab ocean model is used in the other ocean basins. This model configuration is referred to as ATL-Mix. In the ATL-Mix simulation, the eddy stream function (Fig. 4a: shaded) associated with the decadal Atlantic SST variations exhibits an anomalous zonal dipole-like structure, consistent with the observed pattern (Fig. 3b: shaded). This anomalous dipole pattern corresponds to a low-level convergence of wind anomalies towards the ME (Fig. 4a: vector). The anomalous southerly flow in the low troposphere transports warm moist air from the Indian Ocean over an extremely hot and dry ME landmass, and supports ascending motion in the lower levels. The ME is largely a precipitation free region, and summertime precipitation mostly occurs over the southwestern regions of the Saudi Arabia and Yemen, which remain under the influence of the monsoon flow during this time of the year. The anomalous southerly flow carries more moisture over the region (Fig. $4 \mathrm{~b}$ : contour) and can trap more longwave radiation, which in turn leads to less longwave heat loss from the surface, and finally results in a net increase of the surface temperatures (Fig. $4 \mathrm{C}$ ). The regression of simulated net surface downward longwave radiation flux (DLWRF) onto the ATL index corroborates this hypothesis (Fig. 4b: shaded) showing an anomalous increase of DLWRF over the ME, in conjunction with enhanced moisture flow from the neighboring water bodies. 

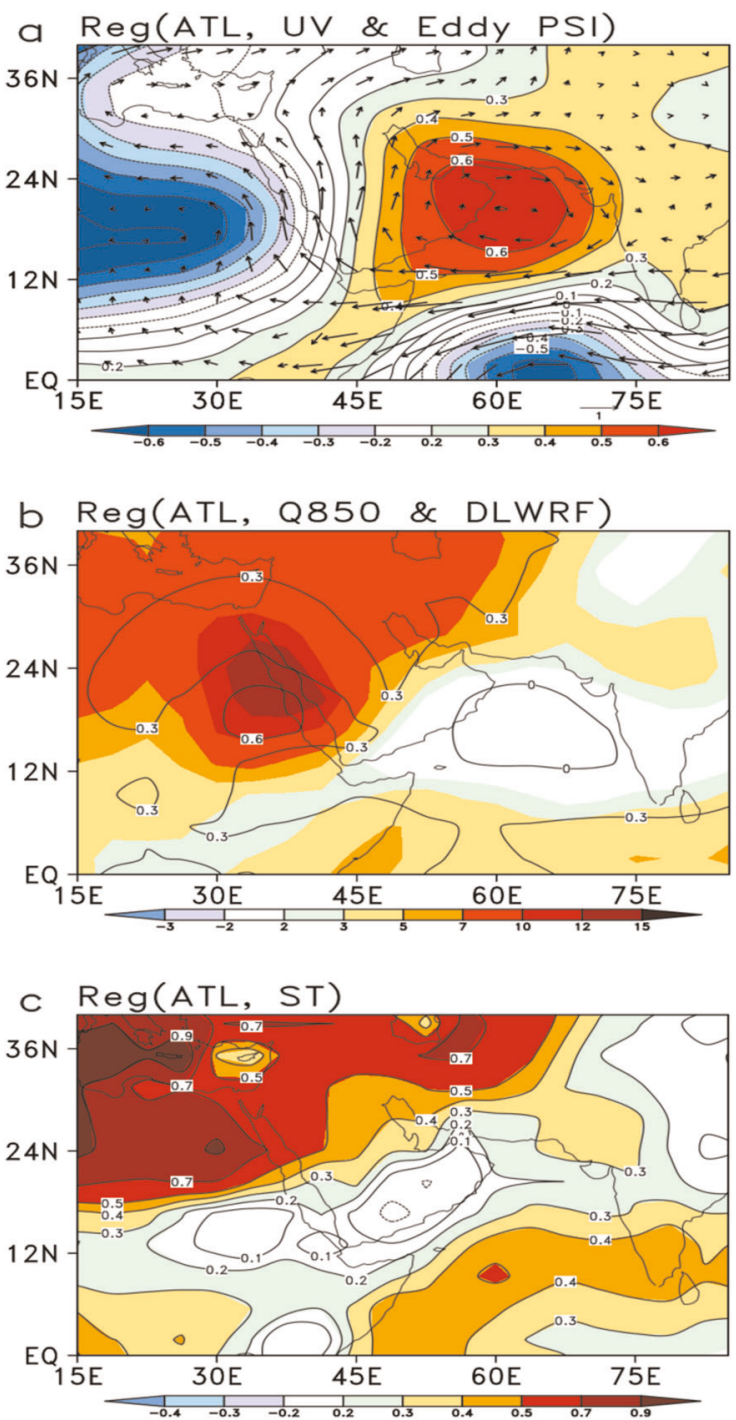

Fig. 4 Modeled response of Atlantic on the lower atmosphere of the ME by SPEEDY AGCM Pacemaker simulations. a The regression of Atlantic SST index with eddy stream function (shaded: $\times 1 \mathrm{e}+$ $06 \mathrm{~m}^{2} \mathrm{~s}^{-1}$ ) and winds at $850 \mathrm{hPa}$ (vector: $\mathrm{m} \mathrm{s}^{-1}$ ). b Same as a but for lower level-specific humidity (contour: $\mathrm{g} \mathrm{kg}^{-1}$ ) and downward longwave radiation (shaded: $\mathrm{W} \mathrm{m}^{-2}$ ). c Same as a but for surface temperature (shaded: ${ }^{\circ} \mathrm{C}$ ) over the Arabian Peninsula for the period 1948-2014. Color regions display significant values by using MC method with $95 \%$ confidence level.

To further investigate how the Atlantic multidecadal variability modulates the ME climate, we use an additional set of idealized experiments, performed with the CMCC-CM2-SR5 global coupled model following the well-established CMIP6 DCPP-C protocol $^{47}$ (see the models and experiments). In these experiments, the model SST over the North Atlantic is restored towards an estimate of the observed SST pattern associated with a positive or negative AMV phase (while leaving freely evolving the remaining part of the model domain. The impact of AMV is assessed through difference patterns between AMV+ and AMVcomposite fields. First, we analyze changes in the upper-level atmospheric circulation. In particular, focusing on the meridional wind velocity at $200 \mathrm{hPa}$ (Fig. 5a: contours), the anomalous signal suggests a wave train-like response linking the North Atlantic Ocean to the Eurasian continent, in line with previous results, ${ }^{29}$ while the zonal component of the wind anomaly exhibits a weakening of the ME jet stream (Fig. 5a: shaded), highlighted by the negative anomalies over the Mediterranean basin, and a strengthening of the polar jet stream, as revealed by the positive anomalies over northern Eurasia. Locally, an east-west pressure dipole anomaly emerges (Fig. 5b: shaded) consistent with the observed pattern shown in Fig. 3b. Consistently, low-level wind anomalies (Fig. 5b: vectors) show a northward flow over the entire region, that implies moisture advection from the Indian Ocean, which leads to a local increase of specific humidity (SHUM, Fig. 5c: contours). The AMV+ induced DLWRF (Fig. $5 c$ : shaded) reflects the SHUM field with significant, positive anomalies, covering the entire domain and preventing surface heat loss. Therefore, surface temperatures rise over the northern latitudes of ME (Fig. 5d), consistently with positive geopotential anomalies at $300 \mathrm{hPa}$ (Fig. 5e).

\section{DISCUSSION}

The Middle East is hyper-arid and is one of the hottest regions in the world during summertime. The current research presents observational evidence and numerical simulations indicating that Atlantic multidecadal variability could have a remote influence on the decadal variability of ME summer SAT. The main findings from this study are summarized below:

- The leading mode of summer ME-SAT is characterized by positive anomalies all over the region and explains a substantial fraction (42.5\%) of the total variability; the associated time series shows significant multidecadal variations.

- Correlation analysis indicates a significant in-phase relationship between the summer ME-SAT and AMV in observations, and the ME-SAT decadal variability can be largely explained by the AMV signal.

- The decadal variation of summer ME-SAT is strongly affected by an east-west pressure dipole pattern over the region, which supports an anomalous southerly flow that brings warm moist air from the Indian Ocean over an extremely hot and arid ME region.

- Idealized modeling experiments advocate that the teleconnection pattern excited by North Atlantic SST warming associated with positive AMV phase show a northward flow over the entire region consistent with an east-west pressure dipole anomaly.

- The AMV induced anomalous circulation changes are reflected in the downward longwave radiation with significant, positive anomalies, which cover the entire domain, prevent surface heat loss, and lead to an increase in summer ME-SAT.

Several recent studies $^{48}$ have discussed the anomalously increasing trend of SST in the Red Sea, and further provide evidence that these increasing trends are modulated by the $\mathrm{AMV}+$ through atmospheric teleconnection. Our suite of idealized numerical simulations (including both Atlantic Pacemaker and DCPP-Component $C$ experiments) also faithfully reproduce the summer ME-SAT multidecadal variability and the basin-wide north Atlantic SST connection. Current conclusions suggest that the Atlantic Ocean acts as a critical pacemaker for the summer ME-SAT variability on multidecadal timescales. These findings also suggest that the recent pattern of summer ME climate may be expected to continue as long as the present warm phase of the AMV persists, though, it is uncertain how long this will continue. Understanding the nature and drivers of the transition from warm to cold AMV phase and their impacts on the Middle East climate will be a goal of future research.

\section{METHODS}

We consider the boreal summer season. The observed and simulated seasonal mean anomalies for a given year are calculated by subtracting the 

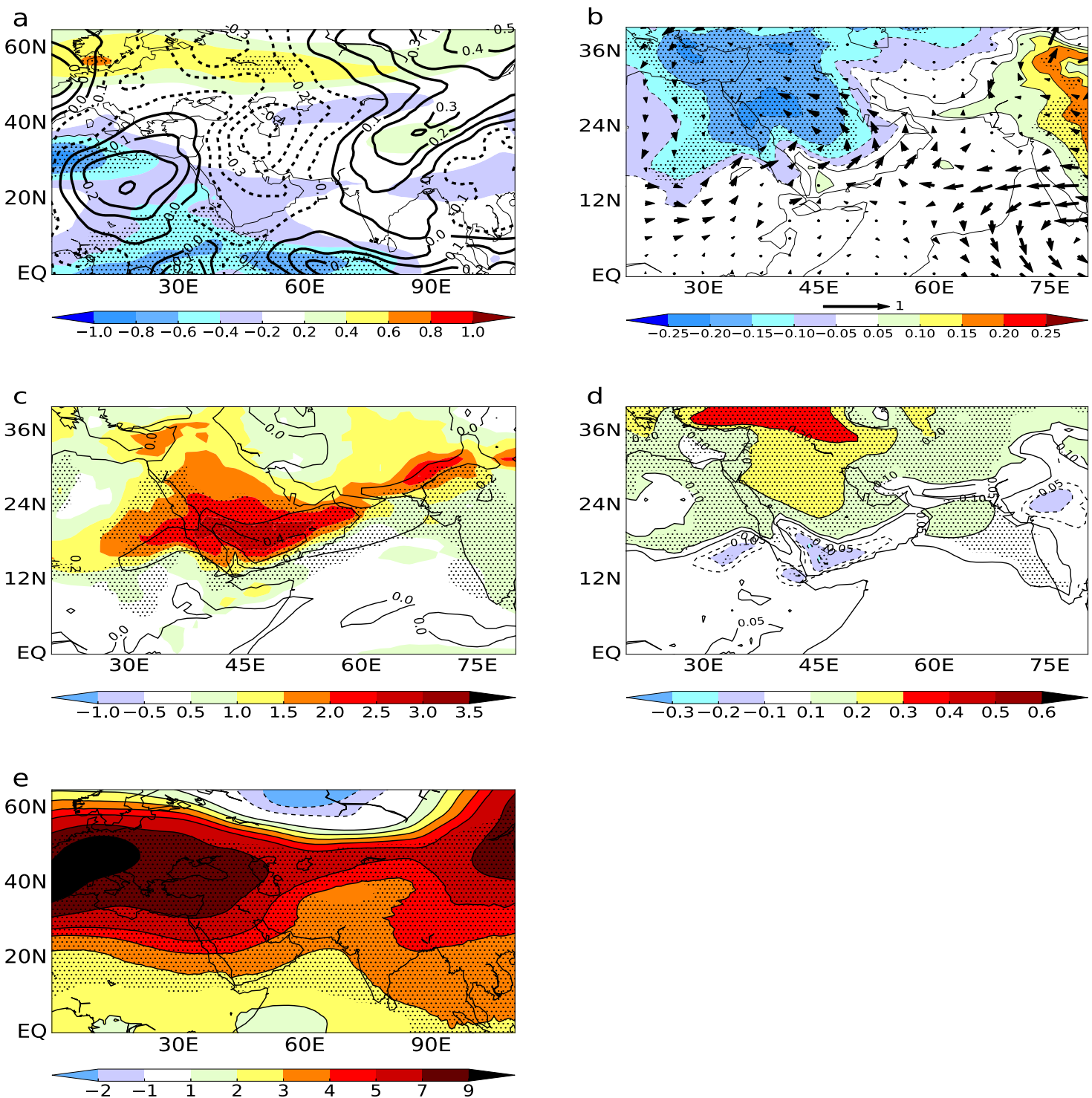

Fig. 5 Impact of positive and negative phases of AMV on ME summer climate by CMCC CGCM CMIP6 AMV Pacemaker simulations. Boreal summer (JJA) difference between the last 9-year ensemble mean of the positive and negative phases of the AMV experiments for a $200 \mathrm{hPa}$ zonal (U200 ( $\left.\mathrm{m} \mathrm{s}^{-1}\right)$ : shaded) and meridional (V200 ( $\left.\mathrm{m} \mathrm{s}^{-1}\right)$ : contour) winds, b Mean sea level pressure (MSLP (hPa): shaded) and $850 \mathrm{hPa}$ winds (UV850 ( $\left.\mathrm{m} \mathrm{s}^{-1}\right)$ : vectors) c Downward longwave radiation flux at surface (DLWRF $\left(\mathrm{W} \mathrm{m}^{-2}\right)$ : shaded) and specific humidity at $850 \mathrm{hPa}(\mathrm{Q} 850$ $\left(\mathrm{g} \mathrm{kg}^{-1}\right)$ : contour), d SAT $\left({ }^{\circ} \mathrm{C}\right)$ and e geopotential height $(\mathrm{m})$ at $300 \mathrm{hPa}$. Dotted regions display significant values using two-tailed Student's $t$-test with $95 \%$ confidence level.

observed and simulated overall seasonal mean respectively. As uncertainties in surface observations prior to 2 nd half of twentieth century are relatively large, and therefore earlier data are deemed less reliable, we confine our analysis to a common 69-year period (1948-2016). We remove the long-term linear trend in the variables for all 69 summers by least squares. The idea behind removing the long-term trend is to disentangle the global warming signal and the signal from decadal or multidecadal variability, which has a stronger influence on land surface temperature. The spatial and temporal modes of variability of summer SAT over the ME are obtained from empirical orthogonal function decomposition analysis. ${ }^{49}$ The spatial EOFs are obtained by computing the eigenvalues and eigenvectors of the covariance matrix of SAT. The principal component time series of each mode is estimated by projecting the derived eigenvectors onto the anomalies of summer SAT. Finally, the fields are also multiplied by an area-weighting factor, which is estimated by the square root of the cosine of latitude. We apply EOF analysis to a 69-year time series of ME surface air temperature variations from CRU observation data. We considered only the leading EOF mode as it explains $42.5 \%$ of the total variability, and it is characterized by positive SAT anomalies over the whole ME domain. Other EOFs (2, 3, and 4), also show some structure but are not well defined as EOF1. Therefore, we retained the EOF1 for our further analysis, as it shows strong variability, and also connected with well-known mode of variability at multidecadal timescale.

The statistical significance of the correlation and regression is determined using a Monte Carlo (MC) estimate of statistical significance, ${ }^{49}$ and has the advantage of requiring no statistical assumptions. The main idea behind resampling tests is to construct a group of an artificial data of the same size as the actual data at hand, and then to compute the test statistic of interest for each artificial group. Following this procedure, we randomly scramble the order of a given time series and compute the statistics for the randomly ordered data. ${ }^{50}$ This procedure essentially simulates the null hypothesis that there is no relation between the two variables. The process is repeated until there are 1000 samples, and the threshold for statistical significance is the 95th percentile. Along with the MC method, the statistical robustness of the results is also evaluated by means of a two-tailed Student's $t$-test, with a 95\% confidence level of significance. 
The models and experiments

The models. Idealized experiments were carried with the Simplified Parameterizations primitivE-Equation Dynamics (SPEEDY), ${ }^{51}$ Atmospheric global climate model (AGCM) developed at the Abdus Salam International Center for Theoretical Physics. The version 41 of SPEEDY AGCM used here, has a standard resolution corresponding to a triangular spectral truncation to a total of 30 (T30) wavenumbers with $96 \times 48$ Gaussian grids $\left(3.75^{\circ} \times\right.$ $3.75^{\circ}$ ) and eight vertical levels. In this study, SPEEDY AGCM was coupled to a slab ocean mixed-layer model (SOM). The depth of the mixed layer in SOM is constant throughout the whole simulation period varying from $40 \mathrm{~m}$ in the tropics to $60 \mathrm{~m}$ in the extra-tropics. The variation of mixed-layer temperature is derived from the integration of the net heat flux into the ocean from the atmosphere, which is the sum of surface shortwave and longwave radiations, and sensible and latent heat fluxes. All fluxes are considered positive downward.

In addition to SPEEDY AGCM coupled to a mixed-layer ocean model, we also consider a fully coupled, state-of-the-art dynamical climate model as well. The CMCC-CM2-SR5 is a climate system model ${ }^{52}$ developed the Euro-Mediterranean Center on Climate Change (CMCC) Foundation. Its core is based on the Community Earth System Model except for the ocean component, which is represented by the Nucleus for European Modeling of the Ocean (NEMO). The atmospheric model, Community Atmospheric Model version 5, is characterized by a regular, horizontal grid of $0.9^{\circ} \times$ $1.25^{\circ}$. The vertical resolution encompasses 30 vertical hybrid levels, 13 of which between 2 and $200 \mathrm{hPa}$ to include the lower stratosphere. The ocean component is NEMOv3.6, which is a three-dimensional, free surface, hydrostatic, primitive-equation global ocean general circulation model. In this study, the grid configuration employs ORCA tripolar grid-a global curvilinear ocean grid that has two poles in the Northern Hemisphere located over land. The horizontal mesh has a $1^{\circ}(\sim 100 \mathrm{~km})$ horizontal resolution with a meridional refinement up to $1 / 3^{\circ}$ in the tropical region. The vertical grid has 50 geopotential levels. The sea-ice model is the Community Ice CodE (CICE), sharing the horizontal grid with the ocean in CMCC-CM2-SR5. The land component is the Community Land Model (CLM) version 4.5, which is able to simulate the physical, chemical, and biological processes involving land surface. For this study, the land model is used in its "Satellite Phenology" mode, namely the prognostic carbon-nitrogen model is deactivated, and employs the horizontal grid of the atmospheric component. CLM is coupled with the River Transport Model, which routes liquid and ice runoff from the land surface model to the active ocean to simulate a closed hydrologic cycle.

The experiments. To examine the impact of Atlantic SST variability on the surface air temperature over the Middle East and resultant atmospheric circulation changes, we performed an ensemble of experiments commonly referred to as Atlantic Pacemaker experiments with SPEEDY AGCM. These experiments are designed based on the correlation coefficient distribution shown in Fig. 1b, therein summer ME-SAT PC1 is highly positively correlated with the SST in the north Atlantic region, and weaker signal is observed in the Indian Ocean region. The experiment is referred to as ATL-Mix, in which the SPEEDY AGCM is run coupled with the SOM in the Indo-Pacific region, but monthly varying SST from HadISST are prescribed in the Atlantic basin. The model integration starts in 1872 and runs through 2014. Restarting the model using small initial perturbations, we generate an ensemble of five members. In order to make our analysis consistent and comparable with observation we consider the period from 1948 to 2014.

Apart from SPEEDY AGCM coupled with SOM, we also consider the CMCC fully coupled Earth System Model results to support our analysis. Using the CMCC-CM2-SR5 model, two sets of idealized (pacemaker) experiments have been performed (termed AMV + and AMV- experiments), following the protocol outlined in the Decadal Climate Prediction Project (DCCP). In these experiments, the surface of the North Atlantic Ocean (from $10^{\circ} \mathrm{N}$ to $65^{\circ} \mathrm{N}$ ) is restored towards two patterns that are representative of the internal component of variability on multidecadal timescale. The two patterns are obtained superimposing an observational estimate of the AMV SST anomalies onto the model climatology. ${ }^{53}$ The anomalies are added for AMV+ and subtracted for AMV-. Outside the target region, the model is allowed to freely evolve. To reduce the nonlinear uncertainty related to the internal variability of the climate system, an ensemble of 32 members for each experiment is used. Each simulation is integrated over a 10-year period and uses CMIP6 pre-industrial values as external forcings $\left(\mathrm{CO}_{2}\right.$ is set at $284.32 \mathrm{ppm}, \mathrm{CH}_{4}$ at $808.25 \mathrm{ppb}$ and $\mathrm{N}_{2} \mathrm{O}$ at $273.02 \mathrm{ppb}$ ). To enhance the signal-to-noise ratio, an ensemble of 32 members for each experiment is used. Each simulation is integrated over a 10 -year period. Model response is evaluated as the difference between the ensemble means of the positive and negative phase of AMV experiments, considering the last 9 years of simulation out of 10 (i.e., neglecting the first year to allow a full nudging of the North Atlantic SST).

\section{DATA AVAILABILITY}

Openly available observation datasets obtained from different sources are employed in this study. The global monthly land surface temperature is obtained from the Climate Research Unit (CRU) TS4.01 ${ }^{54}$ (https://crudata.uea.ac.uk/cru/data/hrg/ cru_ts_4.01/), monthly varying sea surface temperature from the Hadley Center SST dataset HadISST1.1 ${ }^{55}$ (https://www.metoffice.gov.uk/hadobs/hadisst/), mean sea level pressure (MSLP), horizontal and meridional winds, geopotential height, specific humidity, precipitable water, stream function, velocity potential, and downward longwave and shortwave radiation flux at surface are obtained from the National Centers for Environmental Prediction-National Center for Atmospheric Research (NCEP/NCAR) reanalysis ${ }^{56}$ (http://www.esrl.noaa.gov/psd/). The model datasets are available from the corresponding author upon reasonable request.

\section{CODE AVAILABILITY}

The data in this study were analyzed and the graphics were created with Grid Analysis and Display System (GrADS). Codes from this study are available from the corresponding author upon request. The SPEEDY AGCM code, is available through the URL https://www.ictp.it/research/esp/models/speedy.aspx.

Received: 16 April 2019; Accepted: 31 December 2019; Published online: 30 January 2020

\section{REFERENCES}

1. Stocker, T. F. et al. Climate Change 2013: The Physical Science Basis. Contribution of Working Group I to the Fifth Assessment Report of the Intergovernmental Panel on Climate Change (eds). Cambridge University Press, Cambridge, United Kingdom and New York, NY, USA, 1535 pp, https://doi.org/10.1017/CBO9781107415324 (2013).

2. Mizyed, N. Impacts of climate change on water resources availability and agricultural water demand in the west bank. Water Resour. Manag. 23, 2015-2029 (2009).

3. Zhou, L. et al. Impacts of wind farms on land surface temperature. Nat. Clim. Chang. 2, 539-543 (2012).

4. Pal, J. S. \& Eltahir, E. A. Future temperature in southwest Asia projected to exceed a threshold for human adaptability. Nat. Clim. Chang. 6, 197-200 (2015).

5. Agnew, M. \& Viner, D. Potential impacts of climate change on international tourism. Tour. Hosp. Res. 3, 37-60 (2001).

6. Burke, M., Hsiang, S. M. \& Miguel, E. Global non-linear effect of temperature on economic production. Nature 527, 235-239 (2015).

7. Almazroui, M., Islam, M. N., Athar, H., Jones, P. D. \& Rahman, M. A. Recent climate change in the Arabian Peninsula: annual rainfall and temperature analysis of Saudi Arabia for 1978-2009. Int. J. Climatol. 32, 953-966 (2012).

8. Almazroui, M., Islam, M. N., Jones, P. D., Athar, H. \& Rahman, M. A. Recent climate change in the Arabian Peninsula: seasonal rainfall and temperature climatology of Saudi Arabia for 1979-2009. Atmos. Res. 111, 25-29 (2012).

9. Almazroui, M., Fahad, S., Islam, M. N. \& Alkhalaf, A. K. Assessing the robustness and uncertainties of projected changes in temperature and precipitation in AR4 global climate models over the Arabian Peninsula. Atmos. Res. 182, 163-175 (2016).

10. Kushnir, Y. Interdecadal variations in the North Atlantic sea surface temperature and associated atmospheric conditions. J. Clim. 7, 141-157 (1994).

11. Zhang, R. \& Delworth, T. L. Simulated tropical response to a substantial weak ening of the Atlantic thermohaline circulation. J. Clim. 18, 1853-1860 (2005).

12. Sutton, R. T. \& Hodson, D. L. R. Atlantic ocean forcing of North American and European summer climate. Science 309, 115-118 (2005).

13. Knight, J. R., Folland, C. K. \& Scaife, A. A. Climate impacts of the Atlantic multidecadal oscillation. Geophys. Res. Lett. 33, L17706 (2006).

14. Kerr, R. A. A. North Atlantic pacemaker for the centuries. Science 288, 1984-1986 (2000).

15. DelSole, T., Tippett, M. K. \& Shukla, J. A significant component of unforced multidecadal variability in the recent acceleration of global warming. J. Clim. 24, 909-926 (2011).

16. Ting, M., Kushnir, Y., Seager, R. \& Li, C. Robust features of Atlantic multidecadal variability and its climate impacts. Geophys. Res. Lett. 38, L17705 (2011).

17. DelSole, T., Jia, L. \& Tippett, M. K. Decadal prediction of observed and simulated sea surface temperatures. Geophys. Res. Lett. 40, 2773-2778 (2013).

18. Mann, M. E., Bradley, R. S. \& Hughes, M. K. Global-scale temperature patterns and climate forcing over the past six centuries. Nature 392, 779-787 (1998). 
19. Gray, S. T., Graumlich, L. J., Betancourt, J. L. \& Pederson, G. T. A tree-ring-based reconstruction of the Atlantic Multidecadal Oscillation since 1567 A.D. Geophys. Res. Lett. 31, 1-4 (2004).

20. Sutton, R. T. \& Dong, B. Atlantic Ocean influence on a shift in European climate in the 1990s. Nat. Geosci. 5, 788-792 (2012).

21. Wang, B. et al. Northern hemisphere summer monsoon intensified by mega-El Niño/Southern Oscillation and Atlantic Multidecadal Oscillation. Proc. Natl Acad. Sci. USA 110, 5347-5352 (2013).

22. Kamae, Y., Li, X., Xie, S. P. \& Ueda, H. Atlantic effects on recent decadal trends in global monsoon. Clim. Dyn. 49, 3443-3455 (2017).

23. Zhang, R. \& Delworth, T. L. Impact of Atlantic multidecadal oscillations on India/ Sahel rainfall and Atlantic hurricanes. Geophys. Res. Lett. 33, L17712 (2006).

24. Mohino, E., Janicot, S. \& Bader, J. Sahel rainfall and decadal to multidecadal sea surface temperature variability. Clim. Dyn. 37, 419-440 (2011).

25. Zhou, Y. \& Wu, Z. Possible impacts of mega-El Niño/Southern Oscillation and Atlantic Multidecadal Oscillation on Eurasian heatwave frequency variability. Q. J. R. Meteorol. Soc. 142, 1647-1661 (2016).

26. Sun, C., Li, J. P. \& Zhao, S. Remote influence of Atlantic multidecadal variability on Siberian warm season precipitation. Sci. Rep. 5, 16853 (2015).

27. Krishnamurthy, L. \& Krishnamurthy, V. Teleconnections of Indian monsoon rainfall with AMO and Atlantic tripole. Clim. Dyn. 46, 2269-2285 (2016).

28. Coumou, D., Di Capua, G., Vavrus, S., Wang, L. \& Wang, S. The influence of Arctic amplification on mid-latitude summer circulation. Nat. Commun. 9, 2959 (2018).

29. Chen, S. \& Wu, R. Interdecadal changes in the relationship between interannual variations of spring North Atlantic SST and Eurasian surface air temperature. J. Clim. 30, 3771-3787 (2017).

30. Hasanean, H. M. \& Almazroui, M. Teleconnections of the tropical sea surface temperatures to the surface air temperature over Saudi Arabia in summer season. Int. J. Climatol. 37, 1040-1049 (2016).

31. Attada, R. et al. Surface air temperature variability over the Arabian Peninsula and its links to circulation patterns. Int. J. Climatol. https://doi.org/10.1002/joc.5821 (2018).

32. Attada, R. et al. Prominent mode of summer surface air temperature variability and associated circulation anomalies over the Arabian Peninsula. Atmos. Sci. Lett. https://doi.org/10.1002/asl.860 (2018).

33. Attada, R. et al. The role of the Indian summer monsoon variability on Arabian Peninsula summer climate. Clim. Dyn. 52, 3389-3404 (2019).

34. Rashid, I. U., Almazroui, M., Saeed S., \& Atif, M. R. Analysis of extreme summer temperatures in Saudi Arabia and the association with large-scale atmospheric circulation. https://doi.org/10.1016/j.atmosres.2019.104659 (2019).

35. Rodwell, M. J. \& Hoskins, B. J. Monsoons and the dynamics of deserts. Q. J. R. Meteorol. Soc. 122, 1385-1404 (1996).

36. Ehsan, M. A., Kucharski, F., Almazroui, M., Ismail, M., Tippett, M. K. Potential predictability of Arabian Peninsula summer surface air temperature in the North American multimodel ensemble. Clim. Dyn. https://doi.org/10.1007/s00382-01904784-3 (2019).

37. Teng, H., Branstator, G., Wang, H., Meehl, G. A. \& Washington, W. M. Probability of US heat waves affected by a subseasonal planetary wave pattern. Nat. Geosci. 6, 1056-1061 (2013).

38. Vigaud, N., Ting, M., Lee, D. E., Barnston, A. \& Kushnir, Y. Multiscale variability in North American summer maximum temperatures and modulations from the North Atlantic simulated by an AGCM. J. Clim. 31, 2549-2562 (2018).

39. Ruprich-Robert, Y. et al. Impacts of the Atlantic multidecadal variability on North American summer climate and heat waves. J. Clim. 31, 3679-3700 (2018).

40. Almazroui, M., Rashid, I. U., Saeed, S. \& Islam, M. N. ENSO influence on summer temperature over Arabian Peninsula: role of mid-latitude circulation. Clim. Dyn. https://doi.org/10.1007/s00382-019-04848-4 (2019).

41. Tyrlis, E., Lelieveld, J. \& Steil, B. The summer circulation over the eastern Mediterranean and the Middle East: influence of the South Asian monsoon. Clim. Dyn. 40, 1103-1123 (2013).

42. Evan, A. T. et al. Water vapor-forced greenhouse warming over the Sahara Desert and the recent recovery from the Sahelian drought. J. Clim. 28, 108-123 (2015).

43. Hall, A. \& Manabe, S. Effect of water vapor feedback on internal and anthropogenic variations of the global hydrologic cycle. J. Geophy. Res. 105, 6935-6944 (2000).

44. Kucharski, F., Bracco, A., Yoo, J. H. \& Molteni, F. Low-frequency variability of the Indian monsoon ENSO relationship and the tropical Atlantic: The "weakening" of the 1980s and 1990s. J. Clim. 20, 4255-4266 (2007).

45. Kucharski, F. et al. Gill Matsuno-type mechanism explains the tropical Atlantic influence on African and Indian monsoon rainfall. Quart. J. Roy. Meteor. Soc. 135, 569-579 (2009).

46. Feudale, L. \& Kucharski, F. A common mode of variability of African and Indian monsoon rainfall. Clim. Dyn. 41, 243-254 (2013).

47. Boer, G. J. et al The decadal climate prediction project. Geosci. Model Dev. Discuss. 9, 3751-3777 (2016)
48. Krokos, G. et al. Natural climate oscillations may counteract Red sea warming over the coming decades. Geophy. Res. Lett. https://doi.org/10.1029/2018GL081397 (2019).

49. Wilks, D. S. Statistical Methods in the Atmospheric Sciences. 2nd edn (Elsevier Publishers, New York, 2006).

50. Ehsan, M. A. et al. Skill and predictability in multimodel ensemble forecasts for Northern Hemisphere regions with dominant winter precipitation. Clim. Dyn. 48, 3309-3324 (2017).

51. Kucharski, F. et al. On the need of intermediate complexity general circulation models a "speedy" example. Bull. Am. Meteorol. Soc. 94, 25-30 (2013).

52. Cherchi, A. et al. Global mean climate and main patterns of variability in the CMCC-CM2 coupled model. J. Adv. Model. Earth Sys. 11, 185-209 (2019).

53. Nicoli, D. Global climate impacts of the atlantic multidecadal variability: a modelbased approach. Ph.D. Thesis Università Ca' Foscari Venezia. http://hdl.handle. net/10579/14983 (2019).

54. Harris, I., Jones, P. D., Osborn, T. J. \& Lister, D. H. Updated high-resolution grids of monthly climatic observations-the CRU TS3.10 Dataset. Int. J. Climatol. 34, 623-642 (2014).

55. Rayner et al. Global analyses of sea surface temperature, sea ice, and night marine air temperature since the late nineteenth century. J. Geophys. Res. 108, 4407 (2003).

56. Kalnay et al. The NCEP/NCAR 40-year reanalysis project. Bull. Am. Meteorol. Soc. 77, 437-470 (1996).

\section{ACKNOWLEDGEMENTS}

D.N., A.B., and P.R. received support from the EU funded H2020 EUCP ("European Climate Prediction System") Project (Grant Agreement nr. 776613). We also acknowledge King Abdulaziz University's High-Performance Computing Center (Aziz Supercomputer: http://hpc.kau.edu.sa) for providing computation support for this work.

\section{AUTHOR CONTRIBUTIONS}

M.A.E. designed the study, analyzed the results, and led the writing of this work. M.A.E. and F.K. discussed the main results section and analyzed SPEEDY modeling simulations. D.N. performed and analyzed the modeling results related to CMCC model. A.B., P.R., I.S.K., M.K.T., and M.A. contributed in discussion and helped shape the research, analysis, and writing of the manuscript.

\section{COMPETING INTERESTS}

The authors declare no competing interests.

\section{ADDITIONAL INFORMATION}

Supplementary information is available for this paper at https://doi.org/10.1038/ s41612-020-0109-1.

Correspondence and requests for materials should be addressed to M.A.E.

Reprints and permission information is available at http://www.nature.com/ reprints

Publisher's note Springer Nature remains neutral with regard to jurisdictional claims in published maps and institutional affiliations.

Open Access This article is licensed under a Creative Commons Attribution 4.0 International License, which permits use, sharing, adaptation, distribution and reproduction in any medium or format, as long as you give appropriate credit to the original author(s) and the source, provide a link to the Creative Commons license, and indicate if changes were made. The images or other third party material in this article are included in the article's Creative Commons license, unless indicated otherwise in a credit line to the material. If material is not included in the article's Creative Commons license and your intended use is not permitted by statutory regulation or exceeds the permitted use, you will need to obtain permission directly from the copyright holder. To view a copy of this license, visit http://creativecommons. org/licenses/by/4.0/.

This is a U.S. government work and not under copyright protection in the U.S.; foreign copyright protection may apply 2020 